Canadian

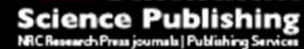

Canadian Journal of Microbiology Revue canadienne de de microbiologie

\title{
Soil microbial communities of three major Chinese truffles in Southwest China
}

\begin{tabular}{|c|c|}
\hline Journal: & Canadian Journal of Microbiology \\
\hline Manuscript ID & cjm-2016-0139.R3 \\
\hline Manuscript Type: & Article \\
\hline Date Submitted by the Author: & 18-Jun-2016 \\
\hline Complete List of Authors: & $\begin{array}{l}\text { Fu, Yu; Sichuan University, Key Laboratory of Bio-resources and Eco- } \\
\text { environment of the Ministry of Education, College of Life Sciences } \\
\text { Li, Xiaolin; Soil and Fertilizer Research Institute, Sichuan Academy of } \\
\text { Agricultural Sciences, Chengdu, Sichuan, China } \\
\text { Li, Qiang; Sichuan university, Key Laboratory of Bio-resources and Eco- } \\
\text { environment of the Ministry of Education, College of Life Sciences } \\
\text { Wu, Haowei; Sichuan University, Key Laboratory of Bio-resources and Eco- } \\
\text { environment of the Ministry of Education, College of Life Sciences } \\
\text { Xiong, Chuan; Sichuan University, Key Laboratory of Bio-resources and } \\
\text { Eco-environment of the Ministry of Education, College of Life Sciences } \\
\text { Geng, Qi; Sichuan University, Key Laboratory of Bio-resources and Eco- } \\
\text { environment of the Ministry of Education, College of Life Sciences } \\
\text { Sun, Honghu; Sichuan University, Key Laboratory of Bio-resources and } \\
\text { Eco-environment of the Ministry of Education, College of Life Sciences } \\
\text { Sun, Qun; Sichuan University, Key Laboratory of Biological Resource and } \\
\text { Ecological Environment of the Ministry of Education, College of Life } \\
\text { Sciences }\end{array}$ \\
\hline Keyword: & $\begin{array}{l}\text { Tuber. pseudoexcavatum, Tuber. sinoaestivum, Tuber. indicum, truffle, } \\
\text { microbial communities }\end{array}$ \\
\hline
\end{tabular}




\section{Soil microbial communities of three major Chinese truffles in Southwest China}

2

$3 \mathrm{Yu} \mathrm{Fu}^{1}$, Xiaolin $\mathrm{Li}^{2}$, Qiang $\mathrm{Li}^{1}$, Haowei $\mathrm{Wu}^{1}$, Chuan Xiong ${ }^{1}$, Qi Geng ${ }^{1}$, Honghu Sun ${ }^{1 \perp}$, Qun $\mathrm{Sun}^{1}{ }^{*}$

4

$5 \quad{ }^{1}$ Key Laboratory of Bio-resources and Eco-environment of the Ministry of Education, College of

6 Life Sciences, Sichuan University, Chengdu, Sichuan 610064, China

$7{ }^{2}$ Soil and Fertilizer Research Institute, Sichuan Academy of Agricultural Sciences, Chengdu,

8 Sichuan, China

$9{ }^{\perp}$ Present address: Chengdu Institutes for Food and Drug Control, Chengdu, Sichuan, China

*Corresponding author:

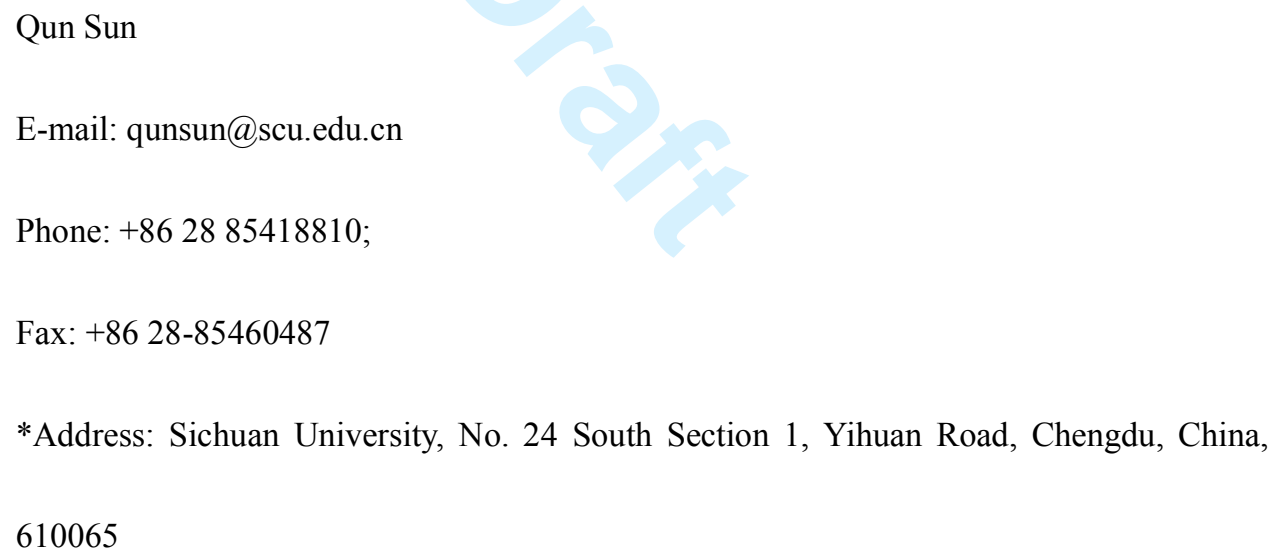

One-sentence summary: Soil microbial communities in T. pseudoexcavatum, T. sinoaestivum, and T. indicum produced in Sichuan, China were disclosed by barcoded pyrosequencing to search microbes potentially attributing to the formation of truffle fruit bodies. 


\section{Abstract:}

Tuber pseudoexcavatum, T. sinoaestivum, and T. indicum are the three most important truffles growing in Southeast China while their cultivation is still of low efficiency, with one important reason being the composition and function of bacterial and fungal community from soils around the fruit bodies and ectomycorrhiza of these truffles remained unclear. The aim of this study was to disclose the microbial communities in truffle-producing soils in Huidong County, Sichuan, China, by barcoded pyrosequencing. Approximately 350,000 quality-controlled sequences were obtained and grouped into 14,025 bacterial operational taxonomic units (OTUs) and 4,385 fungal OTUs, which included 29 bacterial and 7 fungal phyla, respectively. Bacterial genus Acidobacterium and fungal genus Modicella, Pseudogymnoascus, and Mortierella were significantly more abundant in control than in truffle-producing soils $(P<0.05)$, while the bacterial genus Sphingomonas (Alphaproteobacteria) and arbuscular mycorrhizal fungal Glomus were significantly enriched in truffle-producing soil than in control $(P<0.05)$, indicating their different roles within truffle grounds. Notably, some non-fungal organisms detected by $18 \mathrm{~S}$ rDNA pyrosequencing were of high abundance, among which Cercozoa and Ochrophyta were significantly $(P<0.05)$ more abundant in truffle soils than in control, indicating their interactions with truffles.

Key words: Tuber. pseudoexcavatum Tuber. sinoaestivum Tuber. indicum microbial communities truffle 


\section{Introduction:}

Truffles are ectomycorrhizal (ECM) fungi belonging to the Tuber genus (Ascomycota, Pezizales). Truffles produce hypogeous fruiting bodies that are highly appreciated worldwide as foods or seasoning for their richness of amino acids and the unique aroma and flavor. Due to the low yields, the demand for truffles exceeds their supply, especially for Tuber melanosporum (Périgord black truffle), one of the most popular truffles over the world (Mello et al. 2006; Wang et al. 2008; Yun and Hall 2004). The genome sequencing of T. melanosporum expanded our understanding of the reproduction of T. melanosporum and inspired the biological investigation of other Tuber spp. (Martin et al. 2010). T. indicum, T. pseudoexcavatum, and T. sinoaestivum, mainly distributed in Sichuan, Yunnan and Tibet, are the three most important commercial truffle species in southwest China. They serve as a good complement to T. melanosporum (Garcia-Montero et al. 2008). Unfortunately, local farmers, motivated by high reward, tend to pick Chinese truffles before they reach maturity, and this causes a serious threat to the sustainable production of truffles in China. At the same time, there is difficulty in the cultivation of Tuber spp. and the development of their fruiting body in pure culture has not been achieved successfully so far (Kues and Martin 2011; Rubini et al. 2011; Rubini et al. 2007).

Microbial communities are believed to be associated with the maturation of truffle ascocarps and affect their aroma (Barbieri et al. 2005; Barbieri et al. 2007; Splivallo et al. 2015). Some microbes, referred to as rhizosphere "mycorrhization helper bacteria" that promote ectomycorrhizal infection have been reported and received special attention for their potential application in stimulating mycorrhizal root colonization and eventually the truffle production (Garbaye 1994). Ectomycorrhizal fungi biodiversity has been characterized in T. macrosporum, T. 
magnatum, T. melanosporum and T. borchii production sites (Benucci et al. 2014; Guerin-Laguette et al. 2013; Iotti et al. 2010; Leonardi et al. 2013; Murat et al. 2005; Pruett et al. 2008), but non-ectomycorrhizal fungal communities in truffles soil have not been investigated adequately. To our knowledge, no research on associative microbial communities, especially on both bacterial and fungal communities, that participate in the formation and maturation of Chinese truffles has been reported.

Next generation amplicon sequencing is an effective tool to investigate microbial diversity in mixture samples such as stool and soil (Elahi and Ronaghi 2004; Siqueira et al. 2012). Prokaryotes associated with $T$. aestivum ectomycorrhizae and the surrounding soil were investigated using 454-pyrosequencing, and several uncultivable bacterial genera belonging to Pseudonocardineae were identified, indicating their function in modulation of competition with other symbiotic and saprotrophic microbes, facilitation of root penetration and/or accessing mineral nutrients in the soil (Gryndler et al. 2013). However, High-throughput amplicon sequencing has not been used to investigate associative microbial communities of $T$. pseudoexcavatum, $T$. indicum or $T$. sinoaestivum.

In this study, with the aim to disclose microbial communities in soil from truffle grounds and search microbes potentially attributing to the formation of fruit bodies of the three Chinese truffles in Huidong County, Sichuan, China, we analyzed microbial diversity associated with these three truffle species by pyrosequencing of $16 \mathrm{~S}$ rRNA gene V3-V4 region of bacteria and $18 \mathrm{~S}$ rRNA gene V4 region of fungi.

\section{Materials and methods}




\title{
Sampling sites
}

\author{
Soil samples were collected from $T$. pseudoexcavatum, T. sinoaestivum and T. indicum
} grounds at Tangtangzhen, Xueshanxiang, and Xintianxiang in Huidong, respectively $\left(26^{\circ} 22^{\prime}-26^{\circ} 35^{\prime} \mathrm{N}, 102^{\circ} 34^{\prime}-103^{\circ} 57^{\prime}\right.$ E, Liangshan Yi Autonomous Prefecture, Sichuan, China) in January 2015. Ascocarps were collected in Tangtangzhen and Xintianxiang but not in Xueshanxiang (Supplementary 1). In Huidong, the mean annual temperature is $16.2{ }^{\circ} \mathrm{C}$ and the mean annual precipitation is $1,099.7 \mathrm{~mm}$. The sampling sites were mixed forests of Pinus yunnanensis Franch and P. armandii Franch. with sandy loam soil at altitudes from 2,506 m to $2,624 \mathrm{~m}$ above sea level. The major vegetation type of forests where the samples were collected was Pinus armandii, along with a small amount of Platycarya strobilacea, Pyracantha fortuneana, and sparse patches of herbaceous species.

\section{Sampling method and storage}

Samples were collected in Tangtangzhen (TTZ), Xueshanxiang (XSX) and Xintianxiang (XT) where ascocarps of T. pseudoexcavatum, T. sinoaestivum and T. indicum, respectively, had been found during the last three years. Control samples (TTZ-CK, XSX-CK, and XT-CK) were collected from nearby soils (less than 10 meters apart) where truffles were not present. Three soil samples that were less than $5 \mathrm{~m}$ to each other within productive spot were collected. Each sample was composed of $200 \mathrm{~g}$ cylindrical soil cores immediately surrounding $(<5 \mathrm{~cm})$ the fruiting point (20 $\mathrm{cm}$ in depth and $8 \mathrm{~cm}$ in diameter), which was characterized by scanty vegetation. Soil samples and ascocarps were stored in sterile plastic bags less than 3 days at $4{ }^{\circ} \mathrm{C}$ during transport to the laboratory. Prior to storage at $-80{ }^{\circ} \mathrm{C}$, forest debris was removed from the samples.

\section{DNA extraction and amplicon sequencing}


DNA was extracted from $200 \mathrm{mg}$ soil with E.Z.N.A ${ }^{\mathrm{TM}}$ Soil DNA Kit (OMEGA Bio-Tek, U.S.A) following manufacturer's instructions. Ascocarps collected from Tangtangzhen and Xintianxiang were identified as $T$. pseudoexcavatum and $T$. indicum, respectively, by morphological and molecular identification in Soil and Fertilizer Research Institute, Sichuan Academy of Agricultural Sciences. The concentration and quality of the extracted DNA were determined using a Qubit® 2.0 (Invitrogen, USA). The primers for the bacterial 16S rRNA gene and fungal 18S rRNA gene amplicon sequencing were barcoded as described (Supplementary 2) (Langenheder and Szekely 2011; Sun et al. 2014). PCR reactions were performed in a total volume of $50 \mu \mathrm{L}$ containing $5 \mu \mathrm{l}$ of $10 \times$ PCR buffer, $0.5 \mu \mathrm{L}$ dNTPs $(10 \mathrm{mM}$ each), $0.5 \mathrm{uM}$ each primer, 2.5 U Platinum Taq (Thermo, USA) and $10 \mathrm{ng}$ of template DNA. The PCR amplification program included an initial denaturation at $94{ }^{\circ} \mathrm{C}$ for $3 \mathrm{~min}, 5$ cycles of denaturation at $94{ }^{\circ} \mathrm{C}$ for $30 \mathrm{~s}$, annealing at $45^{\circ} \mathrm{C}$ for $20 \mathrm{~s}$, and extension at $65^{\circ} \mathrm{C}$ for $30 \mathrm{~s}$, followed by 20 cycles of denaturation at $94{ }^{\circ} \mathrm{C}$ for $20 \mathrm{~s}$, annealing at $55^{\circ} \mathrm{C}$ for $20 \mathrm{~s}$, and extension at $72{ }^{\circ} \mathrm{C}$ for $30 \mathrm{~s}$, and a final extension at $72^{\circ} \mathrm{C}$ for $5 \mathrm{~min}$. For each sample, three technical replicates of PCR reactions were combined and quantified by agarose gel electrophoresis. Before sequencing, the PCR products were normalized in equal concentration to construct the PCR amplicon libraries. Sequencing was carried out on Illumina MiSeq 2000.

\section{Sequence data analysis}

The sequence reads were sorted into 6 libraries based on their respective barcodes. To minimize the effects of random sequencing errors, the raw sequence reads were checked for their quality. Prinseq was used to remove low-complexity sequences (Schmieder and Edwards 2011).

Chimeras were removed by chimeras.uchime (Edgar et al. 2011). The sequences were grouped 
129

130

131

132

133

134

135

136

137

138

139

140

141

142

143

144

145

146

147

148

149

150

into operational taxonomic units (OTUs) using the 97\% identity threshold (Edgar 2010). OTUs were classified using Ribosomal Database Project (RDP) classifier in Mothur and the database provided by the RDP (http://rdp.cme.msu.edu/) (Wang et al. 2007) and Silva high quality ribosomal RNA databases (http://www.arb-silva.de/). Rarefaction curves were used to estimate coverage. Alpha diversity (the phylogenetic distance whole tree, Chaol and abundance-based coverage estimator (ACE) of richness, observed species, and Shannon's diversity index) and beta diversity (PcoA, UniFrac) were determined using the Mothur software (http://www.mothur.org/) (Yatsunenko et al. 2012; Lozupone and Knight 2005). One-way ANOVA was applied to analyze differences between samples. Relationships between samples were analyzed using principal coordinates analysis (PcoA). A Venn diagram with shared and unique OTUs was used to depict similarities between microbial communities.

\section{Results}

\section{Numbers of OTUs}

To determine the composition of the bacterial and fungal communities colonizing $T$. pseudoexcavatum, T. sinoaestivum and T. indicum truffle soils, we carried out $16 \mathrm{~S}$ and $18 \mathrm{~S}$ rRNA pyrosequencing. After trimming, the $16 \mathrm{~S}$ and $18 \mathrm{~S}$ sequence reads had a mean length of 400-600 bps and an average quality score of 37 . Approximately 350,000 quality controlled sequences were obtained after removal of chimeras and sequences shorter than 200bp. The sequences were clustered into 4,385 fungal OTUs and 14,025 bacterial OTUs at the $97 \%$ similarity threshold. The number of bacterial OTUs in T. pseudoexcavatum soil (TTZ), T. sinoaestivum soil (XSX), and T. indicum soil (XT) were 7,062, 6,781 and 5,541, respectively. A total of 1,279 OTUs were shared 
151 with all three truffle soils (Fig. 1A). A total of 4,385 fungal OTUs were obtained, with 1,510,

152 2,615 and 1,702 OTUs in TTZ, XSX and XT, respectively. A total of 415 fungal OTUs were

153 shared by all three truffle soils (Fig. 1B).

154 Taxonomic classification of bacteria

155 A total of 29 bacterial phyla were identified, out of which 20 were detected in all 18 samples.

156 Proteobacteria (40-59\%), Acidobacteria (8-23.5\%), unclassified (7-10.9\%), Bacteroidetes

157 (1.7-7\%), Planctomycetes (4-11.7\%), and Chloroflexi (1.8-6.4\%) were the most abundant phyla in

158 all soil samples. Proteobacteria were more abundant in truffle soils than in control soils, whereas

159 Acidobacteria were less abundant in truffle soils than in control soils (Fig. 2A).

160 Among the 65 bacterial classes, Alpha-proteobacteria (23\%) and Acidobacteria (17.6\%)

161 were the most abundant. The abundance of Spartobacteria in Verrucomicrobia phylum varied

162 considerably (ranged from $1.3 \%$ to $15.6 \%$ in the samples). Acidobacteria and Acidimicrobiia were

163 less abundant in truffle soils than in control (Fig. 2C).

164 At genus level, Azospira (3.1-5.7\%) was abundant in all samples. Sphingomonas (1.7-12.5\%),

165 Escherichia-Shigella (2.4-5.3\%) and Blastocatella (4.4-5.4\%), within the class

166 Alphaproteobacteria, Gammaproteobacteria, Acidobacteria, respectively, were significantly more

167 abundant in truffle soils than in control soils (ANOVA, $P<0.05$, Table 1). The Acidobacterium

168 (8.3-14.8\%) were significantly more abundant in control soils than in truffle soils.

169 Bacterial community diversity and UniFrac analysis

170 Chaol index in XT was significantly higher than that of $T$. pseudoexcavatum and $T$.

171 sinoaestivum soil samples, as well as than in all control soils (ANOVA, $P<0.05$, Table 2).

172 According to the ACE and Shannon indices XT had significantly higher diversity than other 
173 samples $(P<0.05)$, in spite of lowest sequence numbers. Coverage index showed that sequence

174 efficiency of XT was higher than other samples.

175 UniFrac analysis was performed to estimate the differences in bacterial communities between

176 the samples (Fig. 3). PcoA 3D plot and weighted sample tree showed that the communities in each

177 truffle soil sample were far from the control soil samples in both PcoA 3D plot and weighted

178 sample tree figures (Fig. 3, Supplementary 3). Furthermore, bacterial communities in $T$.

179 pseudoexcavatum-truffle soil (TTZ) were far different from $T$. pseudoexcavatum and $T$.

180 sinoaestivum soil samples (Supplementary 3).

\section{Fungal taxonomic classification}

A total of seven fungal phyla were identified, of which five were identified in all 18 samples. Ascomycota (10-33\%) and Basidiomycota (3.7-11\%) were the dominant phyla in all soil samples. Zygomycota (1.2-37.8\%) were significantly more abundant in control than in truffle soils (ANOVA, $P<0.05)$, while Glomeromycota (1.1-10.7\%) and Chytridiomycota (0.4-4.8\%) were more enriched in truffle soils than in the control (Fig. 2B).

A total of 30 fungal classes were identified. Leotiomycetes (2.7-19.2\%) and Dothideomycetes (3.0-9.4\%) were abundant in all samples. Mucoromycotina (1.2-35.3\%) was significantly abundant in control soils than in truffle soils $(P<0.05)$. Glomeromycetes $(1.1-10.7 \%)$ was more abundant in truffle soils than in control soils (Fig. 2D).

At genus level, Glomus (0.72-16.1\%), belonging to class Glomeromycota, was significantly enriched in three truffle soils as compared with their respective control soil samples (ANOVA, $P<$ 0.05, Table 3). Modicella (0.21-25.3\%), Pseudogymnoascus (0-17.0\%), and Mortierella (0.04-37.4\%) were significantly enriched in control in comparison with the truffle soil samples $(P$ 
195

196

197

198

199

200

201

202

203

204

205

206

207

208

209

210

211

212

213

214

215

216

$<0.05)$.

\section{Fungal community diversity and UniFrac analysis}

The Shannon index of XT was higher than in the other soil samples (ANOVA, $P<0.05$, Table 2). In XSX ACE, Shannon and Chaol indices were lower than in other truffle soils. Coverage index showed that sequence efficiency was balanced in our samples for fungal sequences.

In both the PcoA 3D plot and weighted UniFrac tree, T. pseudoexcavatum control soil (TTZ-CK) was quite close to T. indicum control soil (XT-CK), and T. indicum truffle soil samples were close to T. sinoaestivum truffle soil samples (Fig. 3, Supplementary 3). Fungal communities in each truffle soil sample were different from their corresponding control samples.

\section{Discussion}

Tuber species emit toxic metabolites that can affect the herbaceous cover and roots of host plants in particular Circular zones called 'brûlé' (Streiblova et al. 2012) (Splivallo et al. 2007). Brûlé, where the fruit bodies of T. melanosporum usually are collected, is an area devoid of vegetation. The relationship of microbial communities and ectomycorrhizal fungi within brûlé is interactive and complicated. Soil biodiversity can have a positive or negative effect on fungal growth, distribution and fruiting body formation by altering fungal fitness. In addition, communities of ectomycorrhizal fungi, for example T. aestivum and T. melanosporum, can also alter forest soil biogeochemistry (Mello et al. 2013; Menta et al. 2014). It was also reported that the diversity of soil bacterial communities inside and outside the brûlé was different. Firmicutes, Actinobacteria, and some genera belonging to class Flavobacteriaceae had higher relative 
217

abundances inside the brûlé compared with outside part (Mello et al. 2013). Furthermore, the dynamics of fungal populations seem to be correlated to Brûlé formation (Napoli et al. 2010). The word 'Brûlé' is not used commonly in China, while 'truffle producing ground', the word used in this study instead, represents the small area where Chinese truffles and ectomycorrhizae grow and is characterized by scanty vegetation. To understand the factors associating with truffle growing in this specific area, soil properties were investigated by our group before. It was found that some parameters were different between truffle soils and control. For example, the most suitable $\mathrm{pH}$ values for Chinese truffle growing ranged from 5.53 to 6.64 , and higher than in control. So did total nitrogen. However, the values of silt in truffle soils were lower than in control. Additionally, most properties in truffle soils were relatively similar to each other, while total nitrogen etc. varied within truffle soils. Based on this, the aim of the current study was to investigate microbial community that may make contribution to truffle growing.

\section{Homogeneity and heterogeneity of microbial ecological habitat in Chinese truffle and other}

\section{Tuber species grounds}

In our study, bacterial phylum Proteobacteria had greater representation in the truffle fruiting point soils compared with control soils, whereas the bacterial phylum Acidobacteria had higher relative abundances within control soils compared with truffle soils. Bacterial communities from soils adhering ECMs and ascocarps of T. melanosporum were dominated by proteobacteria, bacteroidetes and Actinobacteria (Antony-Babu et al. 2014), while Actinobacteria, Proteobacteria and Acidobacteria were dominant in both two types of soils (Gryndler et al. 2013). It was reported that Acidobacteria, Actinobacteria and Planctomycetes were of low abundance or even absent in the ascocarp but highly abundant in the soil (Antony-Babu et al. 2014), while in our study, 
Acidobacteria were less abundant in all truffle soils than in control soil samples.

For fungal phylum, Glomeromycota and Chytridiomycota were significantly more abundant in truffle soils compared with control soils, while Zygomycota had higher abundance in control compared with truffle soils. The number of fungal phylum Zygomycota increased inside the $T$. melanosporum brûlé (from 5 to $32 \%$ ) while Basidiomycota decreased (from 61 to $23 \%$ ) in the investigation by Napoli et al (Napoli et al. 2010). Ascomycota were the dominant fungal phylum and their number decreased moving from inside the $T$. melanosporum brûlé to outside, while the number of Basidiomycota increased (Mello et al. 2011). In our study, both Ascomycota and Basidiomycota were abundant, and similarly, Basidiomycota were more abundant in non-truffle soils than in truffle soils, and this might suggest that Basidiomycota played important roles in the ground of T. melanosporum and these three Chinese truffles. Mortierella, belonging to phylum Zygomycota, were significantly enriched in control soils compared with the truffle soils $(\mathrm{P}<0.05)$, while previous study showed they were an equal abundance inside and outside the $T$. melanosporum brûlé (Mello et al. 2011). It suggested that although truffle brûlé might affect soil microbial structure, the exact effect might depend on different Tuber species or geographical location. Our findings may disclose specific microbial ecological habitat of Chinese truffle grounds.

Both bacterial and fungal communities showed differences between truffle-producing and non-producing soils

UniFrac analysis showed that both bacterial and fungal communities of fruit body -producing soils were different from their respective control soils in this study. Different signal intensities of bacteria were presented inside versus outside the $T$. melanosporum brûlé by using DGGE and 
261

262

263

264

265

266

267

268

269

270

271

272

273

274

275

276

277

278

279

DNA microarrays (Mello et al. 2013). Mello et al also found that the ratios of ECM: non-ECM fungi were different inside and outside the T. melanosporum brûlé by the use of DGGE and molecular cloning of ITS. The present study supports the previous findings that both bacterial and fungal communities displayed different tendency inside the brûlé from outside part.

The ecological impact of brûlé, which is the specific small area characterized by scanty vegetation where truffle grows, is still under exploring. The present study disclosed the differences of microbial community between tuber spp. growing and non-growing soils. Many studies have demonstrated that some plants perceived specific truffle volatiles and their growth could potentially be inhibited (Splivallo et al. 2011). Previous work on the composition of both fungal and bacterial communities inside and outside $T$. melanosporum brûlé revealed the differences and suggested that truffles have an efficient strategy of ensuring their survival by spreading their metabolites, mainly volatile organic compounds (VOCs) characterized by allelopathic effects on the herbaceous plants and the microorganisms of the rhizosphere (Mello et al. 2013; Napoli et al. 2010). Some microbes like bacterial genus Sphingomonas (Alphaproteobacteria) and arbuscular mycorrhizal fungal genus Glomus were significantly more abundant among these three Tuber grounds compared with non-truffle soils, while some were not. This might be due to the inhibition by truffle metabolites, which may not be effective on all microbes. Additionally, microbial communities and ectomycorrhizal Tuber spp. within burned area were linked since the former might have an impact on truffle development, while few researches have focused on the dominant microbes in fruiting grounds of different Tuber spp so far. In this study, some bacteria like Sphingomonas (class Alphaproteobacteria), Escherichia-Shigella (class Gammaproteobacteria), and Blastocatella (class Acidobacteria) were in greater number in truffle fruiting point, and their 
283

potential relation to the development of truffle fruiting bodies remains to be disclosed.

Unlike Tuber spp., which produces ECM with symbiosis hosts, arbuscular mycorrhizal fungi (AMF) penetrates the cortical cells of the roots of vascular plants and cannot easily be recognized by eyes. It is widely known that AMF are critical links in plant-soil continuum and play a critical role in alleviating plant stress (Zhang et al. 2016). AM fungi also help plants to capture nutrients such as phosphorus, sulfur, nitrogen and micronutrients from the soil. It is believed that the development of the AM symbiosis played a crucial role in the initial colonization of land by plants. Furthermore, AM fungi are affected by various saprotrophic soil microorganisms, changing the root physiology and releasing organics into the soil (Gryndler et al. 2000). New study has recently explored the AMF communities, which thrive in a Tuber melanosporum brûlé, and disclosed that Glomerales were the dominant fungi inside and outside the brûlé (Mello et al. 2015). In our study, fungal genus Glomus was dominant and significantly more abundant in truffle-producing soils than control soils, showing possible correlation of this fungus with truffle presence.

Notably, non-fungal organisms ranging from $19 \%$ to $38 \%$ were detected by pyrosequencing of 18S rRNA gene V4 region, among which Cercozoa and Ochrophyta were dominant and significantly more abundant in all truffle-producing samples than in control (data not shown) $(P<$ 0.05), suggesting that they may also play important roles in truffle grounds.

\section{Method Limitations}

Barcoded pyrosequencing were chosen to compare the bacteria and fungi communities from truffle producing ground and non-truffle ground in this study, because traditional culture method might miss some important tax. However, DNA of dead cell could also be detected by 
305

306

307

308

309

310

311

312

313

314

315

316

317

318

319

320

321

322

323

324

325

326

pyrosequencing, which means some microbes exist in truffle ground might be killed and had no significance in this area. Nevertheless, differences of microbial communities between truffle and non-truffle ground are found in previous and our studies (Gryndler et al. 2013) (Mello et al. 2013) (Mello et al. 2011), which suggested some microbes might be active in this specific area and potentially associated with truffle fructification.

We believe that microbes and truffle in natural truffle-growing ground are interacted and this relationship is quite complicated. Although it was reported that truffle might impact soil bacteria communities (Mello et al. 2013) and fungal dynamics (Napoli et al. 2010), or vice versa, i.e., the specific microbial communities would put influence on the growing of the specific truffle species, more direct evidence is in demand.

\section{Conclusion}

The present study gives a first glimpse into the microbial communities in $T$. indicum, $T$. pseudoexcavatum, and T. sinoaestivum from China, which represents specific microbial ecological habitat of Chinese truffle burned area. Microbes of bacterial genus Sphingomonas and fungal Glomus, as well as some non-fungal organism (Cercozoa and Ochrophyta), were more abundant within truffle-producing grounds, and their roles playing in the truffle growth remained to be disclosed. Targeted experiments are the next steps and the investigation on bacteria and fungi community living in ascocarps were in our consideration in order to understand the communities directly associated with the growth of these truffle species. 
327 This work was supported by the Applied Basic Research Program of Sichuan Province

328 (2015JY0088), Science and Technology Support Project in Sichuan Province (2015NZ0092), and

329 Science and technology Projects for Richening People and Strengthening County in Sichuan

330 Province (Huidong County special).

331

332

\section{Acknowledgements}

This article is dedicated to commemorate Professor ZHENG Linyong from the Sichuan Academy of Agricultural Sciences for his significant contribution to the development of edible mushroom industry in China.

\section{Conflict of interest statement. None declared.}

\section{Reference}

Antony-Babu, S., Deveau, A., Van Nostrand, J.D., Zhou, J., Le Tacon, F., Robin, C., Frey-Klett, P., and

Uroz, S. 2014. Black truffle-associated bacterial communities during the development and maturation of Tuber melanosporum ascocarps and putative functional roles. Environ Microbiol 16(9): 2831-2847. doi: 10.1111/1462-2920.12294.

Barbieri, E., Bertini, L., Rossi, I., Ceccaroli, P., Saltarelli, R., Guidi, C., Zambonelli, A., and Stocchi, V. 2005. New evidence for bacterial diversity in the ascoma of the ectomycorrhizal fungus Tuber borchii Vittad. FEMS Microbiol Lett 247(1): 23-35. doi: 10.1016/j.femsle.2005.04.027.

Barbieri, E., Guidi, C., Bertaux, J., Frey-Klett, P., Garbaye, J., Ceccaroli, P., Saltarelli, R., Zambonelli, A., and Stocchi, V. 2007. Occurrence and diversity of bacterial communities in Tuber magnatum during 
truffle maturation. Environ Microbiol 9(9): 2234-2246. doi: 10.1111/j.1462-2920.2007.01338.x.

Benucci, G.M., Raggi, L., Albertini, E., Csorbai, A.G., and Donnini, D. 2014. Assessment of ectomycorrhizal biodiversity in Tuber macrosporum productive sites. Mycorrhiza 24(4): 281-292. doi: 10.1007/s00572-013-0538-3.

Edgar, R.C. 2010. Search and clustering orders of magnitude faster than BLAST. Bioinformatics 26(19): 2460-2461. doi: 10.1093/bioinformatics/btq461

Edgar, R.C., Haas, B.J., Clemente, J.C., Quince, C., and Knight, R. 2011. UCHIME improves sensitivity and speed of chimera detection. Bioinformatics 27(16): 2194-2200. doi: 10.1093/bioinformatics/btr381Elahi, E., and Ronaghi, M. 2004. Pyrosequencing: a tool for DNA sequencing analysis. Methods Mol Biol 255: 211-219. doi: 10.1385/1-59259-752-1:211.

Garbaye, J. 1994. Helper Bacteria - a New Dimension to the Mycorrhizal Symbiosis. New Phytol 128(2): 197-210. doi: 10.1111/j.1469-8137.1994.tb04003.x

Garcia-Montero, L.G., Di Massimo, G., Manjon, J.L., and Garcia-Abril, A. 2008. New data on ectomycorrhizae and soils of the Chinese truffles Tuber pseudoexcavatum and Tuber indicum, and their impact on truffle cultivation. Mycorrhiza 19(1): 7-14. doi: 10.1007/s00572-008-0198-x.

Gryndler, M., Hrselova, H., and Striteska, D. 2000. Effect of soil bacteria on hyphal growth of the arbuscular mycorrhizal fungus Glomus claroideum. Folia Microbiol (Praha) 45(6): 545-551. doi:10.1007/BF02818724

Gryndler, M., Soukupova, L., Hrselova, H., Gryndlerova, H., Borovicka, J., Streiblova, E., and Jansa, J. 2013. A quest for indigenous truffle helper prokaryotes. Environ Microbiol Rep 5(3): 346-352. doi: $10.1111 / 1758-2229.12014$.

Guerin-Laguette, A., Cummings, N., Hesom-Williams, N., Butler, R., and Wang, Y. 2013. Mycorrhiza 
371

372

373

374

375

376

377

378

379

380

381

382

383

384

385

386

387

388

389

390

391

392

analyses in New Zealand truffieres reveal frequent but variable persistence of Tuber melanosporum in co-existence with other truffle species. Mycorrhiza 23(2): 87-98. doi: 10.1007/s00572-012-0450-2.

Iotti, M., Lancellotti, E., Hall, I., and Zambonelli, A. 2010. The ectomycorrhizal community in natural Tuber borchii grounds. FEMS Microbiol Ecol 72(2): 250-260. doi: 10.1111/j.1574-6941.2010.00844.x

Kues, U., and Martin, F. 2011. On the road to understanding truffles in the underground. Fungal Genetics and Biology 48(6): 555-560. doi: 10.1016/j.fgb.2011.02.002.

Langenheder, S., and Szekely, A.J. 2011. Species sorting and neutral processes are both important during the initial assembly of bacterial communities. ISME J 5(7): 1086-1094. doi: 10.1038/ismej.2010.207

Leonardi, M., Iotti, M., Oddis, M., Lalli, G., Pacioni, G., Leonardi, P., Maccherini, S., Perini, C., Salerni, E., and Zambonelli, A. 2013. Assessment of ectomycorrhizal fungal communities in the natural habitats of Tuber magnatum (Ascomycota, Pezizales). Mycorrhiza 23(5): 349-358. doi: $10.1007 / \mathrm{s} 00572-012-0474-7$.

Lozupone, C., and Knight, R. 2005. UniFrac: a New Phylogenetic Method for Comparing Microbial Communities. Haemophilia 71(12): 8228-8235. doi: 10.1128/AEM.71.12.8228-8235.2005.

Martin, F., Kohler, A., Murat, C., Balestrini, R., Coutinho, P.M., Jaillon, O., Montanini, B., Morin, E., Noel, B., Percudani, R., Porcel, B., Rubini, A., Amicucci, A., Amselem, J., Anthouard, V., Arcioni, S., Artiguenave, F., Aury, J.M., Ballario, P., Bolchi, A., Brenna, A., Brun, A., Buee, M., Cantarel, B., Chevalier, G., Couloux, A., Da Silva, C., Denoeud, F., Duplessis, S., Ghignone, S., Hilselberger, B., Iotti, M., Marcais, B., Mello, A., Miranda, M., Pacioni, G., Quesneville, H., Riccioni, C., Ruotolo, R., Splivallo, R., Stocchi, V., Tisserant, E., Viscomi, A.R., Zambonelli, A., Zampieri, E., Henrissat, B., Lebrun, M.H., Paolocci, F., Bonfante, P., Ottonello, S., and Wincker, P. 2010. Perigord black truffle 
393

394

396

397

398

399

400

401

402

403

404

405

406

407

408

409

410

411

412

413

414

genome uncovers evolutionary origins and mechanisms of symbiosis. Nature 464(7291): 1033-1038.

doi: $10.1038 /$ nature 08867

Mello, A., Ding, G.C., Piceno, Y.M., Napoli, C., Tom, L.M., DeSantis, T.Z., Andersen, G.L., Smalla, K., and Bonfante, P. 2013. Truffle brules have an impact on the diversity of soil bacterial communities.

PLoS One 8(4): e61945. doi: 10.1371/journal.pone.0061945

Mello, A., Lumini, E., Napoli, C., Bianciotto, V., and Bonfante, P. 2015. Arbuscular mycorrhizal fungal diversity in the Tuber melanosporum brule. Fungal Biol 119(6): 518-527. doi: 10.1016/j.funbio.2015.02.003

Mello, A., Murat, C., and Bonfante, P. 2006. Truffles: much more than a prized and local fungal delicacy. Fems Microbiology Letters 260(1): 1-8. doi: 10.1111/j.1574-6968.2006.00252.x

Mello, A., Napoli, C., Murat, C., Morin, E., Marceddu, G., and Bonfante, P. 2011. ITS-1 versus ITS-2 pyrosequencing: a comparison of fungal populations in truffle grounds. Mycologia 103(6): 1184-1193. doi: $10.3852 / 11-027$

Menta, C., García-Montero, L.G., Pinto, S., Conti, F.D., Baroni, G., and Maresi, M. 2014. Does the natural "microcosm" created by Tuber aestivum affect soil microarthropods? A new hypothesis based on Collembola in truffle culture. Appl Soil Ecol 84: 31-37. doi:10.1016/j.apsoil.2014.06.012

Murat, C., Vizzini, A., Bonfante, P., and Mello, A. 2005. Morphological and molecular typing of the below-ground fungal community in a natural Tuber magnatum truffle-ground. FEMS Microbiol Lett 245(2): 307-313. doi: 10.1016/j.femsle.2005.03.019

Napoli, C., Mello, A., Borra, A., Vizzini, A., Sourzat, P., and Bonfante, P. 2010. Tuber melanosporum, when dominant, affects fungal dynamics in truffle grounds. New Phytol 185(1): 237-247. doi: 10.1111/j.1469-8137.2009.03053.x 
415 Pruett, G., Bruhn, J., and Mihail, J. 2008. Temporal dynamics of ectomycorrhizal community 416 composition on root systems of oak seedlings infected with Burgundy truffle. Mycological Research

417 112: 1344-1354. doi: 10.1016/j.mycres.2008.06.005.

418 Rubini, A., Belfiori, B., Riccioni, C., Tisserant, E., Arcioni, S., Martin, F., and Paolocci, F. 2011.

419 Isolation and characterization of MAT genes in the symbiotic ascomycete Tuber melanosporum. New

420 Phytol 189(3): 710-722. doi: 10.1111/j.1469-8137.2010.03492.x.

421 Rubini, A., Riccioni, C., Arcioni, S., and Paolocci, F. 2007. Troubles with truffles: unveiling more of

422 their biology. New Phytologist 174(2): 256-259. doi: 10.1111/j.1469-8137.2007.01976.x

423 Schmieder, R., and Edwards, R. 2011. Quality control and preprocessing of metagenomic datasets.

424 Bioinformatics 27(6): 863-864(862). doi: 10.1093/bioinformatics/btr026

425 Siqueira, J.F., Jr., Fouad, A.F., and Rocas, I.N. 2012. Pyrosequencing as a tool for better understanding

of human microbiomes. J Oral Microbiol 4. doi: 10.3402/jom.v4i0.10743

427

Splivallo, R., Deveau, A., Valdez, N., Kirchhoff, N., Frey-Klett, P., and Karlovsky, P. 2015. Bacteria

428

429

430

431

432

433

434

435

436

associated with truffle-fruiting bodies contribute to truffle aroma. Environ Microbiol 17(8): 2647-2660.

doi: $10.1111 / 1462-2920.12521$.

Splivallo, R., Novero, M., Bertea, C.M., Bossi, S., and Bonfante, P. 2007. Truffle volatiles inhibit growth and induce an oxidative burst in Arabidopsis thaliana. New Phytol 175(3): 417-424. doi: 10.1111/j.1469-8137.2007.02141.x.

Splivallo, R., Ottonello, S., Mello, A., and Karlovsky, P. 2011. Truffle volatiles: from chemical ecology to aroma biosynthesis. New Phytol 189(3): 688-699. doi: 10.1111/j.1469-8137.2010.03523.x.

Streiblova, E., Gryndlerova, H., and Gryndler, M. 2012. Truffle brule: an efficient fungal life strategy.

FEMS Microbiol Ecol 80(1): 1-8. doi: 10.1111/j.1574-6941.2011.01283.x. 
437

438

439

440

441

442

443

444

445

446

447

448

449

450

451

452

453

454

455

456

457

458

459
Sun, W., Zhang, F., He, L., and Li, Z. 2014. Pyrosequencing reveals diverse microbial community associated with the zoanthid Palythoa australiae from the South China Sea. Microb Ecol 67(4): 942-950. doi: 10.1007/s00248-014-0395-4.

Wang, G., Li, Y.Y., Li, D.S., and Tang, Y.J. 2008. Determination of $5 \alpha$-androst-16-en-3 $\alpha$-ol in truffle fermentation broth by solid-phase extraction coupled with gas chromatography-flame ionization detector/electron impact mass spectrometry. Journal of Chromatography B Analytical Technologies in the Biomedical \& Life Sciences 870(2): 209-215. doi: 10.1016/j.jchromb.2008.06.014

Wang, Q., Garrity, G.M., Tiedje, J.M., and Cole, J.R. 2007. Naive Bayesian classifier for rapid assignment of rRNA sequences into the new bacterial taxonomy. Appl Environ Microbiol 73(16):

5261-5267. doi: 10.1128/AEM.00062-07.

Yatsunenko, T., Rey, F.E., Manary, M.J., Trehan, I., Dominguez-Bello, M.G., Contreras, M., Magris, M., Hidalgo, G., Baldassano, R.N., Anokhin, A.P., Heath, A.C., Warner, B., Reeder, J., Kuczynski, J., Caporaso, J.G., Lozupone, C.A., Lauber, C., Clemente, J.C., Knights, D., Knight, R., and Gordon, J.I. 2012. Human gut microbiome viewed across age and geography. Nature 486(7402): 222-227. doi: $10.1038 /$ nature 11053

Yun, W., and Hall, I.R. 2004. Edible ectomycorrhizal mushrooms: challenges and achievements. Canadian Journal of Botany 82(82): 1063-1073. doi: 10.1139/b04-051

Zhang, B., Li, S., Chen, S., Ren, T., Yang, Z., Zhao, H., Liang, Y., and Han, X. 2016. Arbuscular mycorrhizal fungi regulate soil respiration and its response to precipitation change in a semiarid steppe.

Sci Rep 6: 19990. doi: 10.1038/srep19990 


\section{Table and figure legends}

Table 1. The ten most abundant bacterial genera in the truffle-producing and control soil samples. Average percentages are given into brackets. Each value is the mean of three biological replicates. Genera which were significantly more abundant in one sample than another (one-way ANOVA, $P<0.05$ ) are highlighted with bold letters. TTZ $=$ Tangtangzhen sampling site. $\mathrm{XSX}=$ Xueshanxiang. $\mathrm{XT}=$ Xintianxing. $\mathrm{CK}=$ control soil.

Table 2. Richness estimates and diversity indices of bacterial and fungal communities in truffle-producing and control soil samples. Each value is the mean of three biological replicates $( \pm \mathrm{SE})$. Letters indicate significant differences $(P<0.05)$ among the bacterial and fungal communities of the analyzed samples. TTZ $=$ Tangtangzhen sampling site. XSX = Xueshanxiang. $\mathrm{XT}=$ Xintianxing. $\mathrm{CK}=$ control soil.

Table 3. The ten most abundant fungal genera in the truffle-producing and control soil samples. Average percentages are given into brackets. Each value is the mean of three biological replicates. Genera which were significantly more abundant in one sample than another (one-way ANOVA, $\mathrm{P}<0.05$ ) are highlighted with bold letters. TTZ = Tangtangzhen sampling site. $\mathrm{XSX}=$ Xueshanxiang. $\mathrm{XT}=$ Xintianxing. $\mathrm{CK}=$ control soil.

Figure 1. Numbers of shared and site specific bacterial (A) and fungal (B) OTUs. TTZ = Tangtangzhen sampling site. $\mathrm{XSX}=$ Xueshanxiang. $\mathrm{XT}=$ Xintianxiang. $\mathrm{CK}=$ control soil.

Figure 2. Composition of soil bacterial and fungal communities at phylum and class level in truffle-producing and control soil samples. TTZ $=$ Tangtangzhen sampling site. XSX $=$ Xueshanxiang. $\mathrm{XT}=$ Xintianxiang. $\mathrm{CK}=$ control soil. 
482 Figure 3. Principal coordinate analysis based on weighted UniFrac analysis for three truffle soil

483 bacterial and fungal communities. TTZ $=$ Tangtangzhen sampling site. $\mathrm{XSX}=$ Xueshanxiang.

$484 \quad \mathrm{XT}=$ Xintianxiang. $\mathrm{CK}=$ control soil.

485 

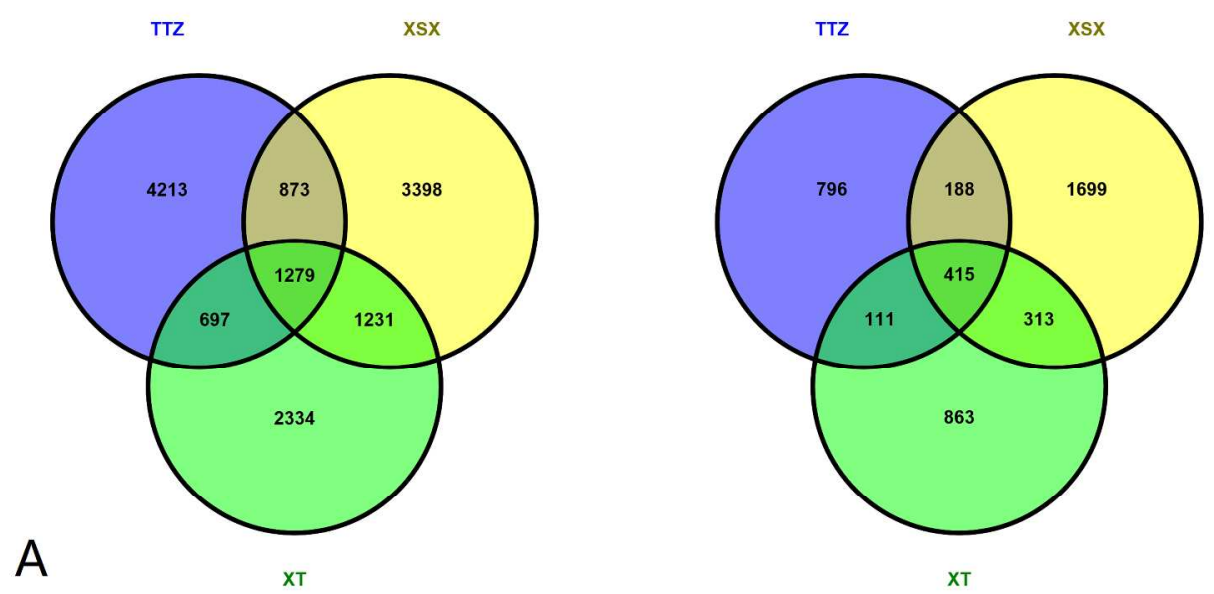

Numbers of shared and site specific bacterial (A) and fungal (B) OTUs. TTZ = Tangtangzhen sampling site. $\mathrm{XSX}=$ Xueshanxiang. $\mathrm{XT}=$ Xintianxiang. $\mathrm{CK}=$ control soil.

$692 \times 338 \mathrm{~mm}(300 \times 300$ DPI $)$ 

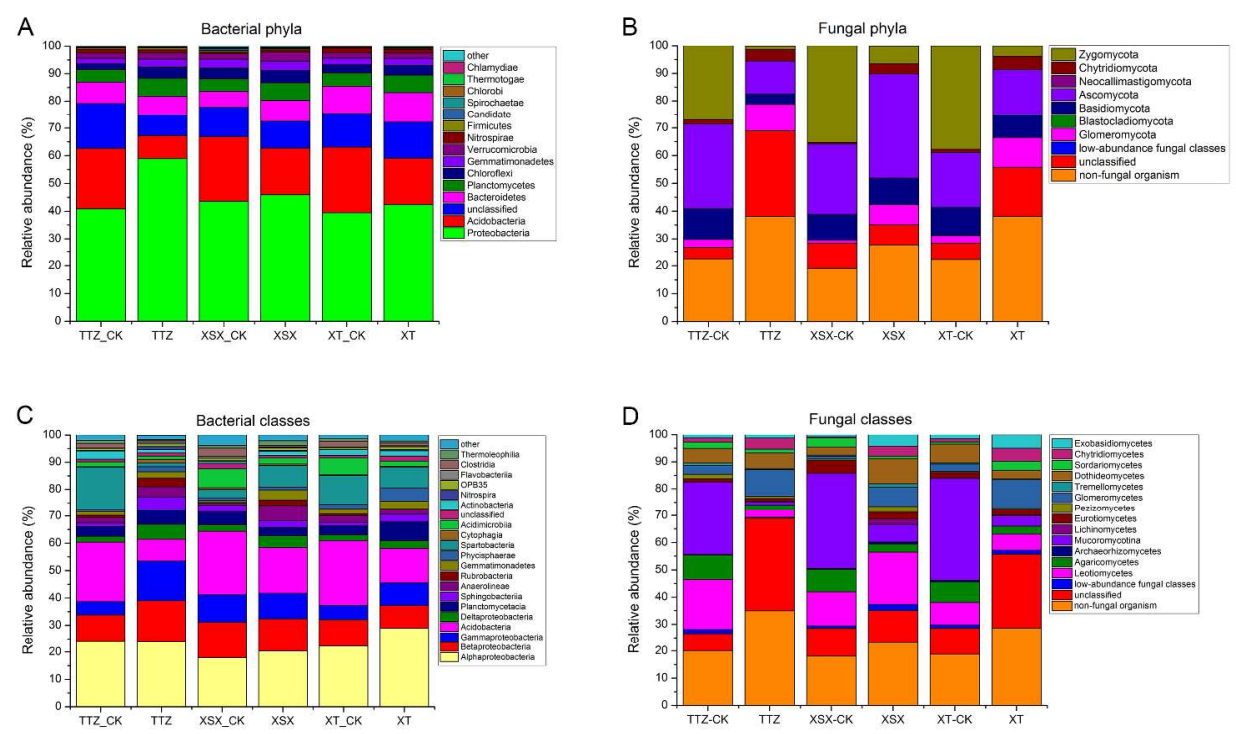

Composition of soil bacterial and fungal communities at phylum and class level in truffle-producing and control soil samples. TTZ $=$ Tangtangzhen sampling site. $\mathrm{XSX}=$ Xueshanxiang. $\mathrm{XT}=$ Xintianxiang. $\mathrm{CK}=$ control soil.

$297 \times 180 \mathrm{~mm}(300 \times 300$ DPI $)$ 

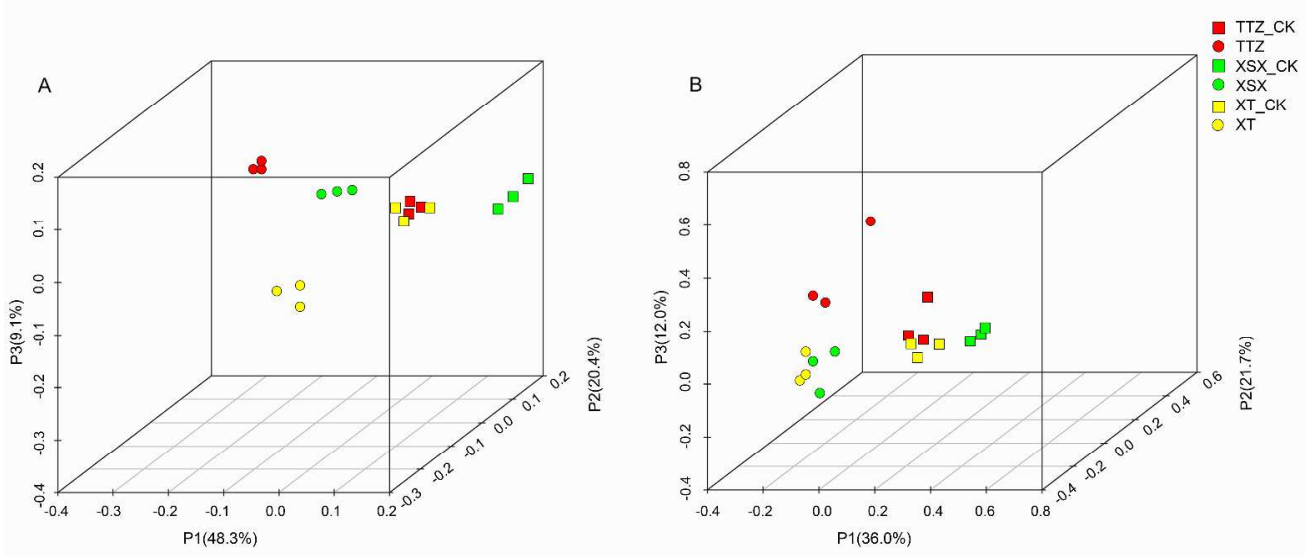

Principal coordinate analysis based on weighted UniFrac analysis for three truffle soil bacterial and fungal communities. TTZ $=$ Tangtangzhen sampling site. $\mathrm{XSX}=$ Xueshanxiang. $\mathrm{XT}=$ Xintianxiang. $\mathrm{CK}=$ control soil.

$642 \times 285 \mathrm{~mm}(300 \times 300$ DPI $)$ 
Table 1. The ten most abundant bacterial genera in the truffle-producing and control soil samples.

\begin{tabular}{|c|c|c|c|c|c|c|}
\hline Samples & $\underline{\text { TTZ-CK }}$ & TTZ & $\underline{\mathrm{XSX}-\mathrm{CK}}$ & XSX & $\underline{\mathrm{XT}-\mathrm{CK}}$ & $\mathrm{XT}$ \\
\hline \multirow{10}{*}{ genera } & Candidatus(20.5) & Sphingomonas(9.2) & Acidobacterium(15.6) & Candidatus(11.2) & Acidobacterium(14.8) & Sphingomonas(12.5) \\
\hline & Acidobacterium(12.2) & Azospira(5.7) & Candidatus(6.3) & Acidobacterium (8.3) & Candidatus(14.0) & Candidatus(10.3) \\
\hline & Sphingomonas(4.5) & Escherichia-Shigella(5.3) & Pseudomonas(4.5) & Sphingomonas(7.8) & Arthrobacter(4.7) & Blastocatella(5.4) \\
\hline & Bradyrhizobium(3.2) & Blastocatella (5.2) & Arthrobacter(4.2) & Blastocatella $(4.4)$ & Sphingomonas(4.3) & $\begin{array}{l}\text { unclassifiedPlanctomycetace } \\
a e(3.5)\end{array}$ \\
\hline & Azospira(3.1) & Rubrobacter(3.1) & Burkholderia(4.1) & Azospira(3.8) & Bradyrhizobium(3.2) & Acidobacterium(3.2) \\
\hline & Defluviicoccus(2.4) & unclassifiedNitrosomonadaceae (2.9) & unclassifiedPlanctomycetaceae(3.6) & Pseudomona (3.8) & Azospira(3.2) & Novosphingobium (3.0) \\
\hline & unclassifiedPlanctomycetaceae(2.3) & Ornatilinea(2.6) & Azospira(2.6) & Ornatilinea(3.3) & Novosphingobium (2.7) & Phycisphaera(2.7) \\
\hline & Bryobacter (2.3) & Candidatus(2.6) & Skermanella(2.3) & Novosphingobium (3.1) & Blastocatella(2.5) & Azospira(2.5) \\
\hline & Novosphingobium(2.2) & unclassifiedChitinophagaceae(2.6) & Bryobacter(2.2) & $\begin{array}{l}\text { unclassified } \\
\text { Gemmatimonadaceae(2. } \\
\text { 8) }\end{array}$ & $\begin{array}{l}\text { UnclassifiedComamonadace } \\
\operatorname{ae}(2.4)\end{array}$ & Escherichia-Shigella(2.4) \\
\hline & Blastocatella $(2.0)$ & unclassifiedRhodospirillaceae(2.4) & unclassified(2.0) & $\begin{array}{l}\text { Escherichia-Shigella(2. } \\
\text { 4) }\end{array}$ & Bryobacter (2.1) & $\begin{array}{l}\text { unclassifiedGemmatimonada } \\
\text { сеae }(2.4)\end{array}$ \\
\hline
\end{tabular}

Average percentages are given into brackets. Each value is the mean of three biological replicates. Genera which were significantly more abundant in one sample than another (one-way ANOVA, $P<0.05$ ) are highlighted with bold letters. TTZ $=$ Tangtangzgen sampling site. XSX $=\mathrm{Xueshanxiang}$. XT $=\mathrm{Xintianxing}$. CK $=$ control soil. 
Table 2. Richness estimates and diversity indices of bacterial and fungal communities in truffle-producing and control soil samples.

\begin{tabular}{|c|c|c|c|c|c|c|c|c|}
\hline & Sample & Seq num & OTUs num & Shannon_index & ACE_index & Chao 1_index & Coverage_index & Simpson_index \\
\hline \multirow{6}{*}{$\begin{array}{c}\text { Bacterial } \\
\text { alpha } \\
\text { diversities }\end{array}$} & XSX-CK & 33572 & 7695 & $7.4326 \pm 0.3^{\mathrm{c}}$ & $25165 \pm 5729^{b}$ & $16460 \pm 3047^{b}$ & $0.8632 \pm 0.03^{\mathrm{a}}$ & $0.004202 \pm 0.0014^{\mathrm{a}}$ \\
\hline & XSX & 31422 & 6686 & $7.4436 \pm 0.06^{\mathrm{c}}$ & $20093 \pm 1656^{\mathrm{b}}$ & $13820 \pm 633^{b}$ & $0.8791 \pm 0.01^{\mathrm{a}}$ & $0.003118 \pm 0.00049^{\mathrm{a}}$ \\
\hline & TTZ-CK & 24110 & 6774 & $7.6992 \pm 0.06^{\mathrm{b}}$ & $34588 \pm 2931^{\mathrm{a}}$ & $19198 \pm 2556^{\mathrm{b}}$ & $0.7344 \pm 0.19^{\mathrm{ab}}$ & $0.001817 \pm 0.0006^{\mathrm{b}}$ \\
\hline & TTZ & 34903 & 7412 & $7.6359 \pm 0.06^{\mathrm{bc}}$ & $23215 \pm 4756^{\mathrm{b}}$ & $16018 \pm 2253^{b}$ & $0.8787 \pm 0.02^{\mathrm{a}}$ & $0.002050 \pm 0.0001^{\mathrm{b}}$ \\
\hline & XT-CK & 18534 & 6309 & $7.6499 \pm 0.15^{\mathrm{bc}}$ & $33018 \pm 8347^{\mathrm{a}}$ & $18039 \pm 2907^{b}$ & $0.7439 \pm 0.09^{\mathrm{ab}}$ & $0.002889 \pm 0.0001^{\mathrm{b}}$ \\
\hline & $\mathrm{XT}$ & 16496 & 7405 & $8.1511 \pm 0.10^{\mathrm{a}}$ & $42802 \pm 8286^{\mathrm{a}}$ & $23641 \pm 2280^{\mathrm{a}}$ & $0.6519 \pm 0.11^{\mathrm{b}}$ & $0.001741 \pm 0.0006^{\mathrm{b}}$ \\
\hline \multirow{6}{*}{$\begin{array}{c}\text { Fungal } \\
\text { alpha } \\
\text { diversities }\end{array}$} & XSX-CK & 12692 & 1709 & $5.15 \pm 0.60^{\mathrm{ab}}$ & $4643 \pm 262^{\mathrm{ab}}$ & $3478 \pm 146^{\mathrm{bc}}$ & $0.91 \pm 0.02$ & $0.04 \pm 0.02$ \\
\hline & XSX & 9131 & 1042 & $4.67 \pm 01.08^{\mathrm{a}}$ & $3070 \pm 1080^{\mathrm{a}}$ & $2161 \pm 447^{\mathrm{a}}$ & $0.94 \pm 0.02$ & $0.10 \pm 0.14$ \\
\hline & TTZ-CK & 12666 & 1867 & $5.34 \pm 0.21^{\mathrm{ab}}$ & $6159 \pm 315^{\mathrm{b}}$ & $4062 \pm 229^{b}$ & $0.93 \pm 0.01$ & $0.03 \pm 0.01$ \\
\hline & TTZ & 17621 & 2083 & $5.86 \pm 0.20^{\mathrm{b}}$ & $4978 \pm 2090^{b}$ & $3947 \pm 1408^{\mathrm{b}}$ & $0.93 \pm 0.02$ & $0.02 \pm 0.01$ \\
\hline & XT-CK & 11547 & 1579 & $5.20 \pm 0.18^{\mathrm{ab}}$ & $4413 \pm 440^{\mathrm{ab}}$ & $3117 \pm 208^{\mathrm{ab}}$ & $0.93 \pm 0.02$ & $0.04 \pm 0.01$ \\
\hline & $\mathrm{XT}$ & 9801 & 1505 & $6.00 \pm 0.10^{\mathrm{b}}$ & $3655 \pm 167^{\mathrm{ab}}$ & $2812 \pm 244^{\mathrm{ac}}$ & $0.92 \pm 0.01$ & $0.01 \pm 0.00$ \\
\hline
\end{tabular}

Each value is the mean of three biological replicates $( \pm \mathrm{SE})$. Letters indicate significant differences $(P<0.05)$ among the bacterial and fungal communities of the analyzed samples. TTZ $=$ Tangtangzgen sampling site. XSX $=$ Xueshanxiang. XT $=$ Xintianxing. $\mathrm{CK}=$ control soil. Letters indicate significant differences $(P<0.05)$ among treatments. 
Table 3. The ten most abundant fungal genera in the truffle-producing and control soil samples.

\begin{tabular}{|c|c|c|c|c|c|c|}
\hline Samples & $\underline{\text { TTZ-CK }}$ & TTZ & $\underline{\mathrm{XSX}-\mathrm{CK}}$ & XSX & $\underline{\mathrm{XT}-\mathrm{CK}}$ & $\mathrm{XT}$ \\
\hline \multirow{10}{*}{ Genera } & Mortierella(20.5) & Glomus(8.3) & Modicella(24.2) & Xylogone(14.3) & Mortierella(30.2) & Glomus(8.6) \\
\hline & Pseudogymnoascus(13.2) & Lophium(4.5) & Mortierella (10.9) & Glomus(5.3) & Modicella(7.3) & Malassezia(4.9) \\
\hline & Modicella(6.4) & Septoglomus(1.4) & Xylogone (5.1) & Mortierella (4.4) & Pseudogymnoascus(5.5) & Pseudogymnoascus(3.4) \\
\hline & Coprinus(5.6) & Fimicolochytrium(1.3) & Pseudogymnoascus(3.8) & Malassez(4.2) & Polyozellus(4.2) & Mortierella(2.5) \\
\hline & Herpotrichia(0.9) & Malassezia(1.2) & Russula(3.5) & Boeremia(3.0) & Herpotrichia(3.1) & $\operatorname{Grosmannia}(2.1)$ \\
\hline & Glomus(2.2) & Tetracladium(0.9) & Athelia(2.6) & Modicella(2.0) & Glomus(1.8) & Fimicolochytrium(1.9) \\
\hline & Tetracladium(2.1) & Isaria $(0.9)$ & Trichoderma(2.4) & Thyrea(1.9) & Malassezia(1.5) & Septoglomus(1.7) \\
\hline & Inocybe(1.6) & Inocybe $(0.9)$ & Exophiala(1.6) & Lophium(1.7) & Lophium(1.3) & Lentinula(1.4) \\
\hline & Cadophora(1.2) & Powellomyces(0.7) & Cadophora(1.2) & Tuber(1.6) & Trechispora(1.0) & Herpotrichia(1.1) \\
\hline & Malassezia(1.2) & Xylogone $(0.7)$ & Herpotrichia $(0.9)$ & Pseudogymnoascus(1.3) & Mytilinidion(0.9) & Modicella(1.0) \\
\hline
\end{tabular}

Average percentages are given in the brackets. Each value is the mean of three biological replicates. Genera that are significantly more abundant in one sample than another (one-way ANOVA, $P<0.05$ ) are highlighted with bold letters. TTZ $=$ Tangtangzgen sampling site. XSX $=$ Xueshanxiang. XT $=$ Xintianxing. $\mathrm{CK}=$ control soil. 